\title{
Steroid Synthesis Inhibition with Ketoconazole and its Effect upon the Regulation of the Hypothalamus-Pituitary-Adrenal System in Healthy Humans
}

\author{
Michael Deuschle*,', Olivera Lecei', Günther K Stalla², Rainer Landgraf', Bettina Hamann', Florian \\ Lederbogen', Manfred Uhr', Peter Luppa ${ }^{3}$, Athanasios Maras', Michael Colla ${ }^{1,4}$ and Isabella Heuser ${ }^{1,4}$ \\ 'Central Institute of Mental Health, Mannheim, Germany; ${ }^{2}$ Max Planck Institute of Psychiatry, Munich, Germany; ${ }^{3}$ Institute of Clinical Chemistry \\ \& Pathobiochemistry, Technical University, Munich, Germany; ${ }^{4}$ Department of Psychiatry, Free University of Berlin, Germany
}

\begin{abstract}
Steroid synthesis inhibitors are commonly used in the treatment of patients with Cushing's disease, but may also improve psychopathology in hypercortisolemic depressed patients. Since glucocorticoids exert a negative feedback at pituitary and supra-pituitary levels, the inhibition of steroid synthesis may lead to increased expression of corticotropin-releasing hormone $(\mathrm{CRH})$ and arginine vasopressin (AVP). We studied the effect of treatment with $800 \mathrm{mg}$ ketoconazole (3 weeks) upon the concentrations of basal plasma cortisol in the evening, corticosteroid-binding globulin (CBG), dehydroepiandrosterone-sulfate (DHEA-S), and ACTH as well as the concentrations of cortisol, $\mathrm{CRH}$, and AVP in cerebrospinal fluid (CSF) at $8.30 \mathrm{~h}$ in 10 healthy, male volunteers. While we found cortisol plasma concentrations to be unchanged, we noted a significant increase in ACTH (post: $45.1 \pm 43.5$; pre: $14.2 \pm 5.2$ pmol//; $F_{1,8}=9.78$, $p<0.02$ ) and CBG concentrations (post: $38.8 \pm 4.3$; pre: $31.9 \pm 4.2 \mu \mathrm{g} /$ ), but DHEA-S plasma concentrations declined (post: $1.75 \pm$ ।.83; pre: $\left.2.75 \pm 2.80 \mathrm{mg} / \mid ; F_{1,8}=7.9, p<0.03\right)$. CRH concentrations in CSF were unchanged after treatment (post: $62.5 \pm 15.9 ;$ pre: $63.7 \pm 13.9 \mathrm{pg} / \mathrm{ml}$ ), while there was a trend for AVP concentrations to rise during treatment (post: $2.52 \pm 1.18$; pre: $1.92 \pm 0.96 \mathrm{pg} /$ $\mathrm{ml}$; paired $t=-1.9, p<0.1$ ). Cortisol CSF concentrations declined in the elderly (pre: $52.5 \pm 23.2$; post: $26.7 \pm 4.6 \mathrm{nmol} / \mathrm{l}$ ), but not in the young subgroup (pre: $15.6 \pm$ II.3; post: $27.7 \pm 9.4 \mathrm{nmol} / \mathrm{l}$ ). We thus conclude that the treatment of healthy controls with steroidsynthesis inhibitors does not lead to a major increase in $\mathrm{CRH}$ secretion.

Neuropsychopharmacology (2003) 28, 379-383. doi:I 0.1038/sj.npp. 1300044
\end{abstract}

Keywords: HPA; cortisol; ACTH; CRH; vasopressin; CBG; DHEA-S; steroid synthesis; plasma; CSF

\section{INTRODUCTION}

It is a well-established finding that hypothalamus-pituitary-adrenal (HPA) system dysregulation is common in depressed patients with evidence for both increased central HPA system activity (Arborelius et al, 1999) and pituitarydriven hypercortisolemia (Deuschle et al, 1997a,b). Both the central regulator of the HPA system, corticotropinreleasing hormone (CRH), as well as its effector steroid cortisol have been discussed to be pathophysiologically relevant in depression (Wolkowitz and Reus, 1999; Holsboer 1999, 2000). In line with these assumptions, amelioriation of depression is preceded by normalization of both CRH and cortisol (Heuser et al, 1996, 1998).

This study was supported by a grant of the Deutsche Forschungsgemeinschaft to MD and IH (DFG De 660/4-I).

* Correspondence: Dr M Deuschle, Central Institute of Mental Health, J5, 68I59 Mannheim, Germany, Tel: +49 62I 1703 626, Fax: +49 62I |703 89|, E-mail: deuschle@as200.zi-mannheim.de

Received 24 February 2002; revised 22 July 2002; accepted 24 July 2002

Online publication: 12 August 2002 at http://www.acnp.org/citations/ Npp081202360
These findings stimulated research on the antidepressive properties of CRH receptor antagonists (Holsboer 1999) and antiglucocorticoid drugs (Wolkowitz and Reus, 1999; Wolkowitz et al, 1999a, b), the latter also being used as palliative treatment of Cushing's syndrome (Loli et al, 1986). Recently, the first report about successful antidepressive and antianxiety properties of a $\mathrm{CRH}$ antagonist has been published (Zobel et al, 2000). Also, a number of controlled and uncontrolled trials supported the assumption that steroid synthesis inhibiting drugs exert antidepressive activity in hypercortisolemic depressed patients (Wolkowitz and Reus, 1999).

The HPA system is under the strong control of glucocorticoids, which exert a negative feedback at the level of the hippocampus, hypothalamus, and pituitary (Holsboer, 2000). Therefore, lowering the concentration of glucocorticoids leads to a complex pattern of activation of the central nervous elements of the HPA system, possibly including increased activity of the central regulators CRH and arginine vasopressin (AVP) (Kovacs et al, 2000; Ma and Aguilera, 1999; Schmidt et al, 1997; Ixart et al, 1994). Owing to behavioral effects of CRH and AVP, this may counteract the antidepressive properties of antiglucocorticoid drugs 
(Holsboer, 1999; Scott and Dinan, 1998; Ebner et al, 1999). However, one must also consider that lowering cortisol concentrations could potentially promote anxiolytic effects by decreasing $\mathrm{CRH}$ levels in the central nucleus of the amygdala (Schulkin et al, 1998).

Since antidepressant treatment with ketoconazole is increasingly acknowledged as an option for treatmentresistant depressed patients with hypercortisolemia (Wolkowitz and Reus, 1999), the effect of steroid synthesis inhibition upon the central regulation of the HPA system deserves closer attention.

Although HPA system regulation differs in various aspects when looking at depressed patients and healthy controls, we were interested in the effect of the steroid synthesis inhibitor ketoconazole upon the regulation of the HPA system in healthy subjects. As in humans HPA system regulation increases during adulthood (Deuschle et al, 1997a,b), we opted to choose to study the effects upon ketoconazole in both young and elderly subjects in order to control for age-dependent effects. We expected that ketoconazole treatment would lower cortisol and dehydroepiandrosterone-sulfate (DHEA-S) concentrations, the latter of which is known to be an adrenal steroid with low circadian variation. Corticosteroid-binding globulin (CBG) was measured in order to ensure an estimate of free and biologically active glucocorticoids. The concentrations of cortisol, CRH, and AVP in cerebrospinal fluid (CSF) were measured to test the hypothesis that ketoconazole impairs the glucocorticoid feedback and, thereby, increases the concentrations of the central regulator of the HPA system.

\section{SUBJECTS AND METHODS}

\section{Subjects}

This study was carried out in accordance with the Declaration of Helsinki. After giving fully informed written consent, five younger (age: $32.4 \pm 6.1$ years; age range: $26-$ 39 years) and five elderly (age: $75.2 \pm 3.8$ years; age range: 69-79 years) healthy male volunteers participated in the study. All subjects were recruited by advertisements. Physical and psychiatric disorders including abuse of drugs and alcohol were excluded by standardized psychiatric interview, physical examination, and laboratory investigations. None of the subjects was taking any medication or vitamins. Smokers and people working on night shifts were not included. One subject (male, 28 years) refused the second spinal tap and, therefore, we included 11 subjects in order to finally analyze a total of 10 subjects. The study was approved by the local ethics committee.

\section{Methods}

All subjects arrived in the laboratory at $17.00 \mathrm{~h}$ and an intravenous catheter was inserted before $18.00 \mathrm{~h}$. Subjects had been fasting since $15.00 \mathrm{~h}$, with water allowed ad libitum. Between 19.00 and $21.00 \mathrm{~h}$, blood was collected every $30 \mathrm{~min}$, and all samples were immediately centrifuged and stored at $-20^{\circ} \mathrm{C}$ for measurement of cortisol and at $-80^{\circ} \mathrm{C}$ for measurement of ACTH (day 1). Following blood sampling, all subjects spent the night in our research unit with lights off between 24.00 and $8.00 \mathrm{~h}$. At $8.30 \mathrm{~h}$ a spinal tap was performed and $12 \mathrm{~cm}^{3} \mathrm{CSF}$ was collected (day 2), immediately frozen on dry ice, and stored at $-80^{\circ} \mathrm{C}$ prior to the measurement of $\mathrm{CRH}$ and AVP concentrations. The spinal tap was performed under standardized conditions in terms of bed rest, fasting conditions, and position. Up to day 24, all subjects then received increasing doses of ketoconazole (day 7: $600 \mathrm{mg}$; day 14: $800 \mathrm{mg}$ ) divided into four daily doses. On days 23 and 24, respectively, blood samples were again collected between 19.00 and $21.00 \mathrm{~h}$ and a spinal tap was performed at $8.30 \mathrm{~h}$. The last dose prior to blood sampling was given at $12.00 \mathrm{~h}$.

\section{Assays}

Plasma cortisol (ICN Pharmaceuticals) and ACTH (Nichols Institute, San Juan Capristano, California) were measured using commercially available immunoassays. CSF concentrations of $\mathrm{CRH}$ were measured using a sensitive and specific radioimmunoassay after an extraction procedure as described earlier (Stalla et al, 1986). In brief, extraction was performed with a Sep-Pak C18 cartridges-method with a recovery of $60 \%$. In the assay procedure, hCRH was used as a standard and $\mathrm{N}$-tyr-hCRH as tracer after labelling with I125. There was no cross-reactivity of the antiserum with other hypothalamic, pituitary, and pancreatic hormones. The lower limit of detection was $10 \mathrm{pg} / \mathrm{ml}$; the intra and interassay coefficients of variation were below $9 \%$. Vasopressin concentrations were estimated in extracted and lyophilized CSF samples by a highly sensitive and specific radioimmunoassay (detection limit $0.1 \mathrm{pg} / \mathrm{sample;} \mathrm{cross-}$ reactivity with other neuropeptides, including oxytocin, $<0.7 \%$; Landgraf et al, 1995). Serum concentrations of CBG were measured using a competitive I-125 radioimmunoassay from DRG Instruments (Marburg, Germany). Interassay imprecision was found with a coefficient of variation of $5.8 \%$. Serum concentrations of DHEAS were measured using a competitive electrochemiluminescent immunoassay from Roche Diagnostics (Mannheim). Interassay variation was below 4\%. Ketoconazole serum concentrations were analyzed by HPLC (limit of detection: $0.36 \mu \mathrm{g} / \mathrm{ml}$ ).

\section{Statistical Analysis}

The five blood samples taken between 19.00 and $21.00 \mathrm{~h}$ were averaged across both sessions and used as the measure of baseline cortisol concentrations. Single samples were used for measurement of CBG, DHEA-S, and ketoconazole. Repeated-measures analyses of variance (ANOVA-rm) and paired $t$-tests were used to assess the effects of 'treatment' and 'generation' $(<40 />65$ years $)$ upon CSF CRH, CSF AVP as well as plasma ACTH, cortisol, CBG, and DHEA-S concentrations.

\section{RESULTS}

Ketoconazole plasma concentrations at $19.00 \mathrm{~h}$ after 22 days of treatment ranged from 1.56 to $11.64 \mu \mathrm{g} / \mathrm{ml}$. There was no difference between young and elderly subjects $(6.45 \pm 1.75$ vs $6.06 \pm 4.3 \mu \mathrm{g} / \mathrm{ml}$ ). Generally, ketoconazole treatment was well tolerated and all liver function tests as well as blood count and serum electrolytes were well within normal limits after ketoconazole treatment. 
ANOVA-rm revealed no significant effect of 'generation' and 'treatment' (pre: $94.4 \pm 68.5$; post: $114.3 \pm 80.2 \mathrm{nmol} / \mathrm{l}$; $\mathrm{F}_{4,72}=0.44$, n.s.) upon cortisol plasma concentrations. There was no significant 'generation' $\times$ 'treatment' interaction effect $\left(\mathrm{F}_{1,64}=2.4\right.$, n.s. $)$.

In contrast, there was a significant increase in ACTH concentrations after ketoconazole treatment (effect of 'treatment': $\left.F_{1,8}=9.78, p<0.02\right)$, which tended to be higher in the elderly compared to the younger subgroup (effect of 'generation': $\left.\mathrm{F}_{1,8}=5.0, p<0.06\right)$. ACTH concentrations significantly increased in young $(t=2.64, p<0.05)$ and elderly subjects $(t=6.0, p<0.01)$. Together with a significant 'generation' $\times$ 'treatment' interaction $\left(\mathrm{F}_{1,8}=7.14\right.$, $p<0.03)$, these results indicate ACTH plasma concentrations to be higher in the elderly and, specifically, to strongly increase in the elderly after ketoconazole treatment.

ANOVA-rm revealed a significant effect of 'generation' $\left(\mathrm{F}_{1,8}=6.76, p<0.03\right)$ and a significant 'generation' $\times$ 'treat'treatment' interaction $\left(\mathrm{F}_{1,8}=12.06, p<0.01\right)$ upon cortisol CSF concentrations, which significantly declined in the elderly (pre: $52.5 \pm 23.2$; post: $26.7 \pm 4.6 \mathrm{nmol} / \mathrm{l}$; paired $t=2.87, p<0.05$ ), but not in the young subgroup (pre: $15.6 \pm 11.3$; post: $27.7 \pm 9.4 \mathrm{nmol} / \mathrm{l}$; paired $\mathrm{t}=2.00$, n.s.).

AVP CSF concentrations also tended to increase after ketoconazole treatment $(2.52 \pm 1.18$ vs $1.92 \pm 0.96 \mathrm{pg} / \mathrm{ml}$; paired $t=-1.9 ; p<0.1$ ). Adding the variable 'generation' to the model failed to reveal a 'generation' or 'generation' $x$ 'treatment' interaction effect (all F-values $<1.0$ ).

Neither 'generation' nor 'treatment' nor the 'generation' $\times$ 'treatment' interaction had a significant effect upon CRH concentrations in the CSF (pre vs post: $62.5 \pm 15.9$ vs $63.7 \pm 13.9 \mathrm{pg} / \mathrm{ml}$; all F-values below 0.5 ).

ANOVA-rm revealed a strong effect of 'treatment' upon CBG plasma concentrations $\left(\mathrm{F}_{1,8}=38.4, p<0.001\right)$, which increased in young (pre $v s$ post: $32.8 \pm 5.2 v s 38.0 \pm 4.3 \mu \mathrm{g} /$ 1) and elderly subjects $(30.9 \pm 3.1 v s 39.5 \pm 4.4 \mu \mathrm{g} / \mathrm{l})$. There was no significant 'generation' (F-value: 0.01 ) or 'generation' $\times$ 'treatment' interaction effect upon CBG concentrations (F-value: 2.2 ).

Concerning DHEA-S plasma concentrations, ANOVA-rm showed strong effects of 'generation' $\left(\mathrm{F}_{1,8}=12.5, p<0.01\right)$ and 'treatment' $\left(\mathrm{F}_{1,8}=7.9, p<0.03\right)$. DHEA-S declined in young (pre vs post: $4.77 \pm 2.68$ vs $3.10 \pm 1.72 \mathrm{mg} / \mathrm{l}$ ) and elderly subjects $(0.72 \pm 0.40$ vs $0.41 \pm 0.21 \mathrm{mg} / \mathrm{l})$. Also, there was a trend for a 'generation' $\times$ 'treatment' interaction effect upon DHEA-S plasma concentrations $\left(\mathrm{F}_{1,8}=3.7\right.$, $p<0.1$.

\section{DISCUSSION}

The main findings of our study are that (1) treatment with $800 \mathrm{mg}$ ketoconazole does not reduce evening plasma cortisol concentrations in healthy controls and (2) the increase in ACTH concentrations is not paralleled by changes in CSF CRH concentrations. Also, the plasma concentrations of the adrenal androgen DHEA-S declined significantly, while ketoconazole treatment increased CBG concentrations.

Treatment with steroid synthesis inhibitors is known to lower cortisol in patients with Cushing's disease (Loli et al, 1986). Treating normocortisolemic healthy controls with ketoconazole, we found cortisol unchanged, while ACTH plasma concentrations were significantly increased. Although ACTH increased, it has to be considered that ketoconazole may directly inhibit the pituitary corticotrophe function (Stalla et al, 1989). The availability of cortisol may be hampered by strongly increased CBG concentrations after treatment. Lowered free cortisol concentrations may have contributed to the significant increase in ACTH concentrations. We decided to study plasma cortisol concentrations in the evening since we expected the signal-to-noise ratio to be favorable at the trough of cortisol's circadian curve because of low ACTH activity at this specific time window. This decision may have led to a floor effect and to a false-negative finding regarding cortisol plasma concentrations, especially with regard to the time of circadian peak concentrations. This assumption is supported by lowered morning cortisol concentrations in the CSF of elderly subjects.

Pituitary ACTH secretion is mainly regulated by $\mathrm{CRH}$ and AVP released at the level of the median eminence. Of course, the question arises as to whether the concentration of ACTH during treatment with steroid synthesis inhibitors is upregulated either by CRH or AVP, the latter of which is known to be co-expressed in parvocellular CRH neurons and to potentiate the effects of CRH. We found $\mathrm{CRH}$ concentrations not to increase after ketoconazole treatment, although effects of order or habituation to the stress of CSF sampling cannot be fully excluded. Of course, our data do not allow us to draw conclusions regarding the effects of ketoconazole upon $\mathrm{CRH}$ at other time windows. At the level of the hypothalamus, lowering the feedback of glucocorticoids exerts its effect on vasopressin rather than on CRH gene expression (Kovacs et al, 2000; Ma and Aguilera, 1999), and suppression of the rat HPA system using steroid synthesis inhibitors has been reported to significantly increase the co-storage of AVP in CRH neurons without altering CRH stores themselves (Schmidt et al, 1997). In line with these findings, long-term surgical adrenalectomy is known to strongly increase ACTH secretion in the presence of normal CRH release at the median eminence (Ixart et al, 1994). Also, CRH in CSF is not increased in patients with Addison's disease (Tomori et al, 1983). In accordance with these preclinical and clinical findings, treating healthy male controls with ketoconazole did not change CRH concentrations in lumbar CSF, while AVP concentrations tended to increase (see Figure 1). Without any reason to assume that AVP decreases, this trend in a two-sided test may be of relevance. There is some evidence for the assumption that AVP in human CSF is, at least partly, independent of AVP released into the blood (Jenkins et al, 1980). However, one must keep in mind that both AVP and CRH are expressed not only in the hypothalamus but also in other brain regions.

Since many depressed patients show a disturbed glucocorticoid feedback (Holsboer, 2000), it is premature to transfer our findings from healthy controls to depressed patients. As the impaired feedback sensitivity of depressed patients' HPA system is known to be already associated with increased hypothalamus CRH storage (Raadsheer et al, 1994), it seems possible to assume a further increase in hypothalamic CRH synthesis as a consequence of lowering cortisol synthesis in depressed patients. However, lowering 


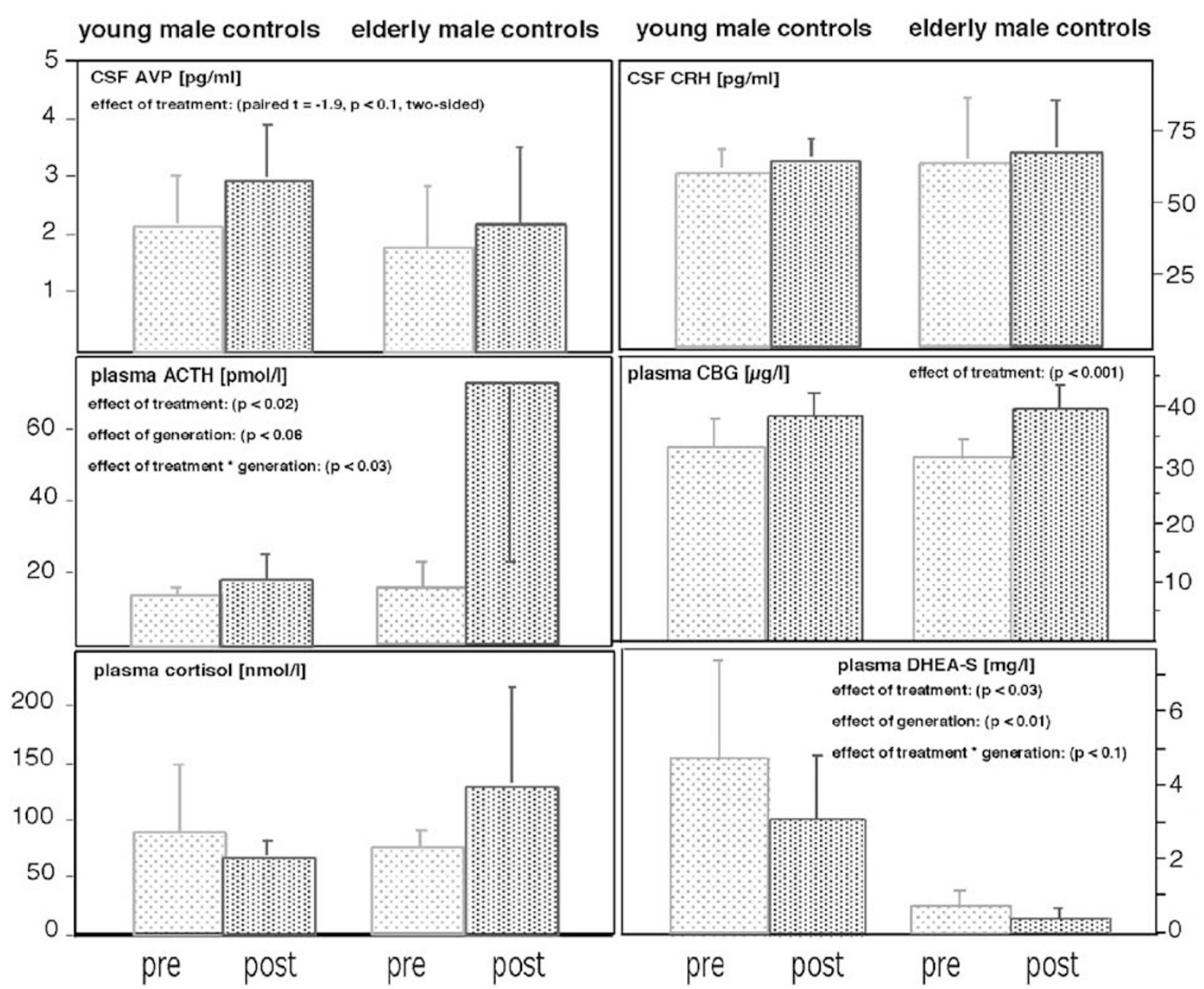

Figure I Mean concentrations of plasma cortisol, DHEA-S, CBG and ACTH, and CSF CRH and AVP concentrations in young and elderly, male healthy controls before (light) and after treatment (dark) with ketoconazole.

glucocorticoid plasma concentrations may not only interfere with CRH synthesis at the hypothalamic site, but also lower CRH storage in the amygdala (Schulkin et al, 1998) and, thereby, exert behavioral effects.

Ketoconazole does not specifically inhibit cortisol synthesis, but interferes with steroid synthesis at various steps. This may explain the finding of lowered DHEA-S plasma concentrations after ketoconazole treatment. Since adrenal androgens and neurosteroids exert independent effects on the brain (Wolkowitz et al, 1999a,b), interaction of ketoconazole with these steroids may have independent psychotropic effects when treating depressed patients.

In conclusion, our data show that treatment with steroid synthesis inhibitors does not result in enhanced secretion of $\mathrm{CRH}$ towards the CSF, at least during the diurnal trough. Therefore, we propose that antidepressive treatment with ketoconazole will not cause a general increase of $\mathrm{CRH}$ secretory activity, but may even lower CRH concentrations in the amygdala.

\section{ACKNOWLEDGMENTS}

We thank Ms Heuer for expert technical assistance and Ms VanSyckel for assisting in the preparation of the manu- script. None of the authors has any conflict of interest with this paper.

\section{REFERENCES}

Arborelius L, Owens MJ, Plotsky PM, Nemeroff CB (1999). The role of corticotropin-releasing factor in depression and anxiety disorders. J Endocrinol 160: 1-12.

Deuschle M, Gotthardt U, Schweiger U, Weber B, Körner A, Schmider J et al (1997a). With aging in humans the activity of the hypothalamus-pituitary-adrenal system increases and its diurnal amplitude flattens. Life Sci 61: 2239-2246.

Deuschle M, Schweiger U, Weber B, Gotthardt U, Körner A, Schmider J et al (1997b). Diurnal activity and pulsatility of the hypothalamus-pituitary-adrenal system in male depressed patients and healthy controls. J Clin Endocrinol Metab 82: 234-238.

Ebner K, Wotjak CT, Holsboer F, Landgraf R, Engelmann M (1999). Vasopressin released within the septal brain area during swim stress modulates the behavioural stress response in rats. Eur J Neurosci 11: 997-1002.

Heuser I, Bissette G, Dettling M, Schweiger U, Gotthardt U, Schmider J et al (1998). Cerebrospinal fluid concentrations of corticotropin-releasing hormone, vasopressin and somatostatin in depressed patients and healthy controls: response to amitriptyline treatment. Depress Anxiety 8: 71-79. 
Heuser I, Schweiger U, Gotthardt U, Schmider J, Lammers C, Dettling $\mathrm{M}$ et al (1996). Pituitary-adrenal-system regulation and psychopathology during amitriptyline treatment in elderly depressed patients and normal comparison subjects. Am J Psychiatry 153: 93-99.

Holsboer F (1999). The rationale for corticotropin-releasing hormone receptor (CRH-R) antagonists to treat depression and anxiety. J Psychiatr Res 33: 181-214.

Holsboer F (2000). The corticosteroid receptor hypothesis of depression. Neuropsychopharmacol 23: 477-501.

Ixart G, Siaud P, Mekaouche M, Barbanel G, Givalois L, Assenmacher I (1994). Short-term but not long-term adrenalectomy modulates amplitude and frequency of the CRH41 episodic release in push-pull cannulated median eminence of free-moving rats. Brain Res 658: 185-191.

Jenkins JS, Mather HM, Ang V (1980). Vasopressin in human cerebrospinal fluid. J Clin Endocrinol Metab 50: 364-367.

Kovacs KJ, Foldes A, Sawchenko PE (2000). Glucocorticoid negative feedback selectively targets vasopressin transcription in parvocellular neurosecretory neurons. J Neurosci 20: 38433852.

Landgraf R, Neumann I, Holsboer F, Pittman QJ (1995). Interleukin-1ß stimulates both central and peripheral release of vasopressin and oxytocin in the rat. Eur J Neurosci 7: 592-598.

Loli P, Berselli ME, Tagliaferri M (1986). Use of ketoconazole in the treatment of Cushing's syndrome. J Clin Endocrinol Metab 63: $1365-1371$.

Ma XM, Aguilera G (1999). Differential regulation of corticotropinreleasing hormone and vasopressin transcription by glucocorticoids. Endocrinology 140: 5642-5650.

Raadsheer FC, Hoogendijk WJ, Stam FC, Tilders FJ, Swaab DF (1994). Increased numbers of corticotropin-releasing hormone expressing neurons in the hypothalamic paraventricular nucleus of depressed patients. Neuroendocrinology 60: 436-444.

Schmidt ED, Janszen AW, Binnekade R, Tilders FJ (1997). Transient suppression of resting corticosterone levels induces sustained increase of AVP stores in hypothalamic CRH neurons of rats. J Neuroendocrinol 9: 69-77.

Schulkin J, Gold PW, McEwen BS (1998). Induction of corticotropin-releasing hormone gene expression by glucocorticoids: implication for understanding the states of fear and anxiety and allostatic load. Psychoneuroendocrinol 23: 219-243.

Scott LV, Dinan TG (1998). Vasopressin and the regulation of hypothalamic-pituitary-adrenal axis function: implications for the pahtophysiology of depression. Life Sci 62: 1985-1998.

Stalla GK, Stalla J, Schopohl J, von Werder K, Müller OA (1986). Corticotropin-releasing factor in humans. Hormone Res 24: 229245.

Stalla GK, Stalla J, von Werder K, Müller OA, Gerzer R, Holt V et al (1989). Nitroimidazole derivates inhibit anterior pituitary cell function appraently by a direct effect on the catalytic subunit of the adenylate cyclase. Endocrinology 125: 699-706.

Tomori N, Suda T, Tozawa F, Demura H, Shizume K, Mouri T (1983). Immunoreactive corticotropin-releasing factor concentrations in cerebropsinal fluid from patients with hypothalamicpituitary-adrenal disorders. J Clin Endocrinol Metab 57: 13051307.

Wolkowitz OM, Reus VI (1999). Treatment of depression with antiglucocorticoid drugs. Psychosom Med 61: 698-711.

Wolkowitz OM, Reus VI, Chan T et al (1999a). Antiglucocorticoid treatment of depression: double-blind ketoconazole. Biol Psychiatry 45: 1070-1074.

Wolkowitz OM, Reus VI, Keebler A, Nelson N, Friedland M, Brizendine L et al (1999b). Double-blind treatment of major depression with dehydroepiandrosterone. Am J Psychiatry 156: 646-649.

Zobel AW, Nickel T, Kunzel HE, Ackl N, Sonntag F, Ising M et al (2000). Effects of the high-affinity corticotropin-releasing hormone receptor 1 antagonist R121919 in major depression: the first 20 patients treated. J Psychiatr Res 34: 171-181. 